\title{
Ampulla of Vater Neuroendocrine Tumor by AJCC V8 Stage
}

National Cancer Institute

\section{Source}

National Cancer Institute. Ampulla of Vater Neuroendocrine Tumor by A/CC v8 Stage.

NCI Thesaurus. Code C135081.

A term that refers to the staging of an ampulla of Vater neuroendocrine tumor according to the American Joint Committee on Cancer, 8th edition. This staging system applies to well-differentiated neuroendocrine tumors of the ampulla of Vater.

Carcinomas of the ampulla of Vater, including high-grade (grade 3), poorly differentiated neuroendocrine carcinomas are not included in this staging system. (from AJCC 8th Ed.) 